Article

\title{
Feasibility Study on S-Band Microwave Radiation and 3D-Thermal Infrared Imaging Sensor-Aided Recognition of Polymer Materials from End-of-Life Vehicles
}

\author{
Jiu Huang ${ }^{1,2, *}$, Zhuangzhuang Zhu ${ }^{1}$, Chuyuan Tian ${ }^{1}$ and Zhengfu Bian ${ }^{1}$ \\ 1 School of Environment Science and Spatial Informatics, China University of Mining and Technology, \\ Xuzhou 221116, China; zzzhu@cumt.edu.cn (Z.Z.); 07143014@cumt.edu.cn (C.T.); zfbian@cumt.edu.cn (Z.B.) \\ 2 State Key Laboratory for Geomechnics and Deep Underground Engineering, Xuzhou 221116, China \\ * Correspondence: jhuang@cumt.edu.cn; Tel.: +86-151-6223-5176
}

Received: 14 February 2018; Accepted: 25 April 2018; Published: 27 April 2018

\begin{abstract}
With the increase the worldwide consumption of vehicles, end-of-life vehicles (ELVs) have kept rapidly increasing in the last two decades. Metallic parts and materials of ELVs can be easily reused and recycled, but the automobile shredder residues (ASRs), of which elastomer and plastic materials make up the vast majority, are difficult to recycle. ASRs are classified as hazardous materials in the main industrial countries, and are required to be materially recycled up to $85-95 \%$ by mass until 2020. However, there is neither sufficient theoretical nor practical experience for sorting ASR polymers. In this research, we provide a novel method by using S-Band microwave irradiation together with 3D scanning as well as infrared thermal imaging sensors for the recognition and sorting of typical plastics and elastomers from the ASR mixture. In this study, an industrial magnetron array with $2.45 \mathrm{GHz}$ irradiation was utilized as the microwave source. Seven kinds of ELV polymer (PVC, ABS, PP, EPDM, NBR, CR, and SBR) crushed scrap residues were tested. After specific power microwave irradiation for a certain time, the tested polymer materials were heated up to different extents corresponding to their respective sensitivities to microwave irradiation. Due to the variations in polymer chemical structure and additive agents, polymers have different sensitivities to microwave radiation, which leads to differences in temperature rises. The differences of temperature increase were obtained by a thermal infrared sensor, and the position and geometrical features of the tested scraps were acquired by a 3D imaging sensor. With this information, the scrap material could be recognized and then sorted. The results showed that this method was effective when the tested polymer materials were heated up to more than $30^{\circ} \mathrm{C}$. For full recognition of the tested polymer scraps, the minimum temperature variations of $5{ }^{\circ} \mathrm{C}$ and $10.5^{\circ} \mathrm{C}$ for plastics and elastomers were needed, respectively. The sorting efficiency was independent of particle sizes but depended on the power and time of the microwave irradiation. Generally, more than $75 \%$ (mass) of the tested polymer materials could be successfully recognized and sorted under an irradiation power of $3 \mathrm{~kW}$. Plastics were much more insensitive to microwave irradiation than elastomers. With this method, the tested mixture of the plastic group (PVC, ABS, PP) and the mixture of elastomer group (EPDM, NBR, CR, and SBR) could be fully separated with an efficiency of $100 \%$.
\end{abstract}

Keywords: 3D-thermal infrared imaging; microwave heating effect; polymer recognition

\section{Introduction}

Since the beginning of the 21st century, polymer technologies have developed rapidly and been implemented in many fields of industry, which has significantly reformed the behaviors both in 
production and consumption [1-3]. Especially in the vehicle industry, huge amounts of polymer materials including plastics and elastomers have been utilized to take the place of metallic materials in vehicles in order to lighten the weight of cars and further reduce fuel consumption as well as the emissions of pollutants and greenhouse gases [4-8]. In the EU, vehicle land transportation contributes about $20 \%$ of the EU's total $\mathrm{CO}_{2}$ emissions, and the $\mathrm{CO}_{2}$ emissions from land transport increased by about $23 \%$ from 1990 to 2010, which has been estimated to keep increasing in the future [5,7]. China has also had a rapid development both in vehicle production and consumption. In the last decade, the Chinese automotive industry had an annual average growth rate of about 20-25\%. In 2014, the total vehicle production reached about 24 million, which made China the largest automobile producer and consumer in the world [9-11].

Transport is one of the major sources where greenhouse gas emissions are still rising. Currently, light-duty vehicles (LDV)—cars and vans—contribute around $15 \%$ of the $\mathrm{EU}^{\prime} \mathrm{s} \mathrm{CO}_{2}$ emissions in land transport. Heavy-duty vehicles (HDV) - trucks and buses—contribute about $25 \%$ of the EU's $\mathrm{CO}_{2}$ emissions in land transport and occupy about $6 \%$ of the EU's $\mathrm{CO}_{2}$ emissions. Therefore, the EU commission has set corresponding legislation on emissions targets for both new passenger cars and van fleets $[1,5,11,12]$ : For passenger cars, manufacturers are stipulated to produce new cars with emissions less than an average of $130 \mathrm{gCO}_{2} / \mathrm{km}$ until 2015, and less than $95 \mathrm{gCO}_{2} / \mathrm{km}$ until 2020. However, in 2007, the average emissions of passenger cars was about $160 \mathrm{gCO}_{2} / \mathrm{km}$ and in 2011 , this value was about $135.7 \mathrm{gCO}_{2} / \mathrm{km}$. According to fuel consumption, the target in 2015 was approximately $5.6 \mathrm{~L} / 100$ $\mathrm{km}$ of petrol and $4.9 \mathrm{~L} / 100 \mathrm{~km}$ of diesel. The targets until 2020 are $4.1 \mathrm{~L} / 100 \mathrm{~km}$ of petrol and 3.6 $\mathrm{L} / 100 \mathrm{~km}$ of diesel.

For vans, the emissions reduction target was $175 \mathrm{gCO}_{2} / \mathrm{km}$ until 2017 and $147 \mathrm{gCO}_{2} / \mathrm{km}$ until 2020. In 2007, the average emission was about $203 \mathrm{gCO}_{2} / \mathrm{km}$ and in 2010 , this value was about 181.4 $\mathrm{gCO}_{2} / \mathrm{km}$. Towards fuel consumption, the 2017 target was approximately $7.5 \mathrm{~L} / 100 \mathrm{~km}$ of petrol and $6.6 \mathrm{~L} / 100 \mathrm{~km}$ of diesel. The target until 2020 is $6.3 \mathrm{~L} / 100 \mathrm{~km}$ of petrol and $5.5 \mathrm{~L} / 100 \mathrm{~km}$ of diesel.

In order to fulfill the requirements of the $\mathrm{CO}_{2}$ emissions reduction, the weight reduction of the entire vehicle is an effective method. Therefore, more polymer materials have been developed and utilized in vehicles. With a weight reduction of $10 \%$, fuel consumption can be decreased by about $6-8 \%$, and every $100 \mathrm{~kg}$ of polymer materials can replace $200-300 \mathrm{~kg}$ of metallic materials. The application of polymers in passenger cars is higher than other kinds of vehicles, for example, the polymer application in a Santana (VW, Wolfsburg, Germany) is about $110 \mathrm{~kg}$ and in a VW Audi $\mathrm{A6}^{\odot}{ }^{\odot}$ it is about $145 \mathrm{~kg}$. Furthermore, in mini buses and trucks, it ranges between about $150 \mathrm{~kg}$ (Styer1491 ${ }^{\odot}, \mathrm{MAN}$, Munich, Germany) and $220 \mathrm{~kg}$ (Iveco $\odot$, VOLVO, Gothenburg, Sweden). In some newly designed cars, e.g., the Audi $2^{\odot}{ }^{\odot}$, the polymer parts represent a total of $300 \mathrm{~kg}$, which is $28.8 \%$ of the total mass. This tendency can be shown by the vehicle material consumption in Figure 1 [3].

By 2020, the polymer material in vehicles is estimated to become more than $25 \%$ by mass. However, the increase in polymer utilization has caused serious problems in the disposal and recycling of end-of-life vehicles (ELVs) since the average life of vehicles is only about 8-15 years. To address this problem, nowadays most countries with vehicle industries have been encouraged to develop mechanisms and technologies for the reuse, recovery, and recycling of ELVs through legislation [1-4,10]. 


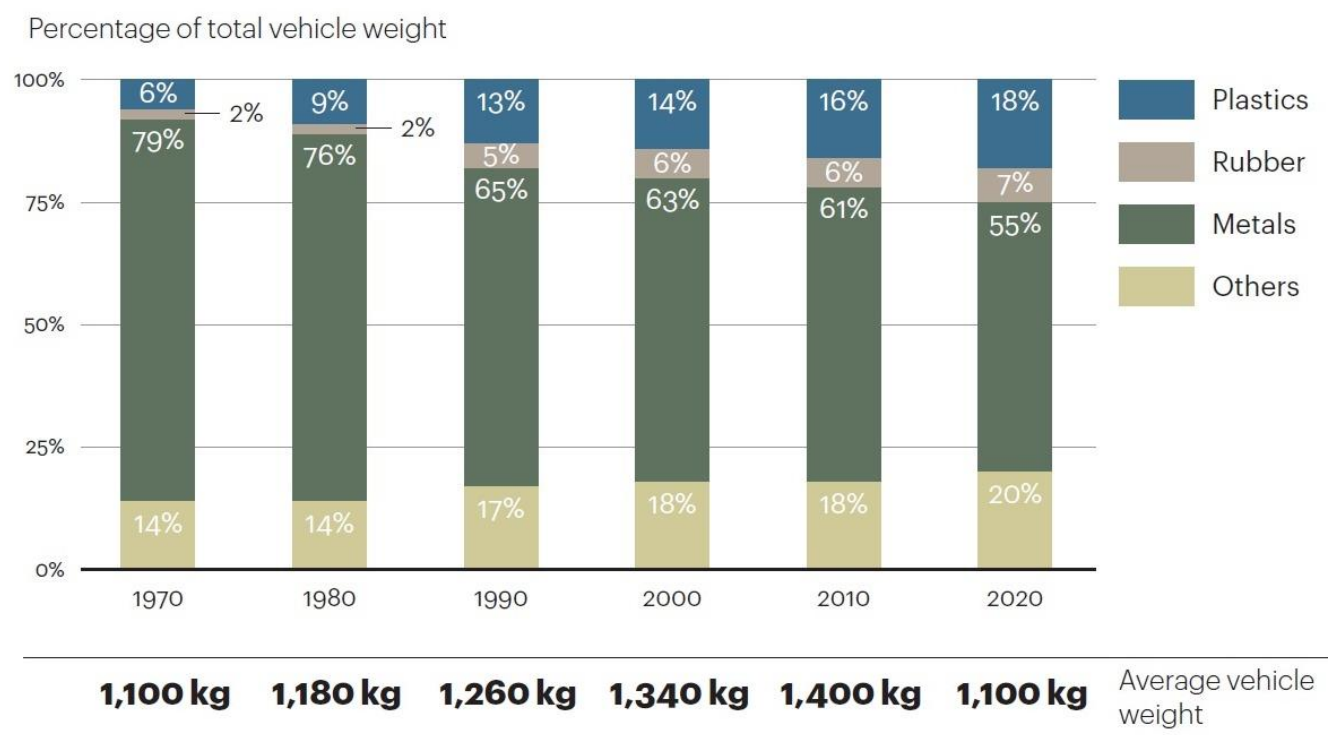

Figure 1. Material consumption of vehicles.

The actual recycling process of ELVs is as follows: first, ELVs arrive at an authorized treatment facility (ATF). There they are de-registered and de-polluted by the removal of batteries, tires, fluids, lubricants, and other hazardous and toxic materials. Then, they are further manually dismantled for reusable or recyclable parts [12-19]. After de-pollution and dismantling, the remaining vehicle-hulks are sent to a shredder where they are crushed into a mixture of small pieces. Then, the ferrous scraps are separated with a purity of more than $99 \%$ from the main stream by a magnetic sorter $[1,4,10,16]$. Next, non-ferrous fractions are sorted by an eddy current separator, which takes up to $6.7 \%$ of the original ELV mass $[12,16]$. After recovering the ferrous and nonferrous components, the rest of the waste stream still represents $15-25 \%$ of the original ELV mass and is known as "Automobile Shredder Residues" or "ASR". Figure 2 summarizes the recycling process of ELVs:

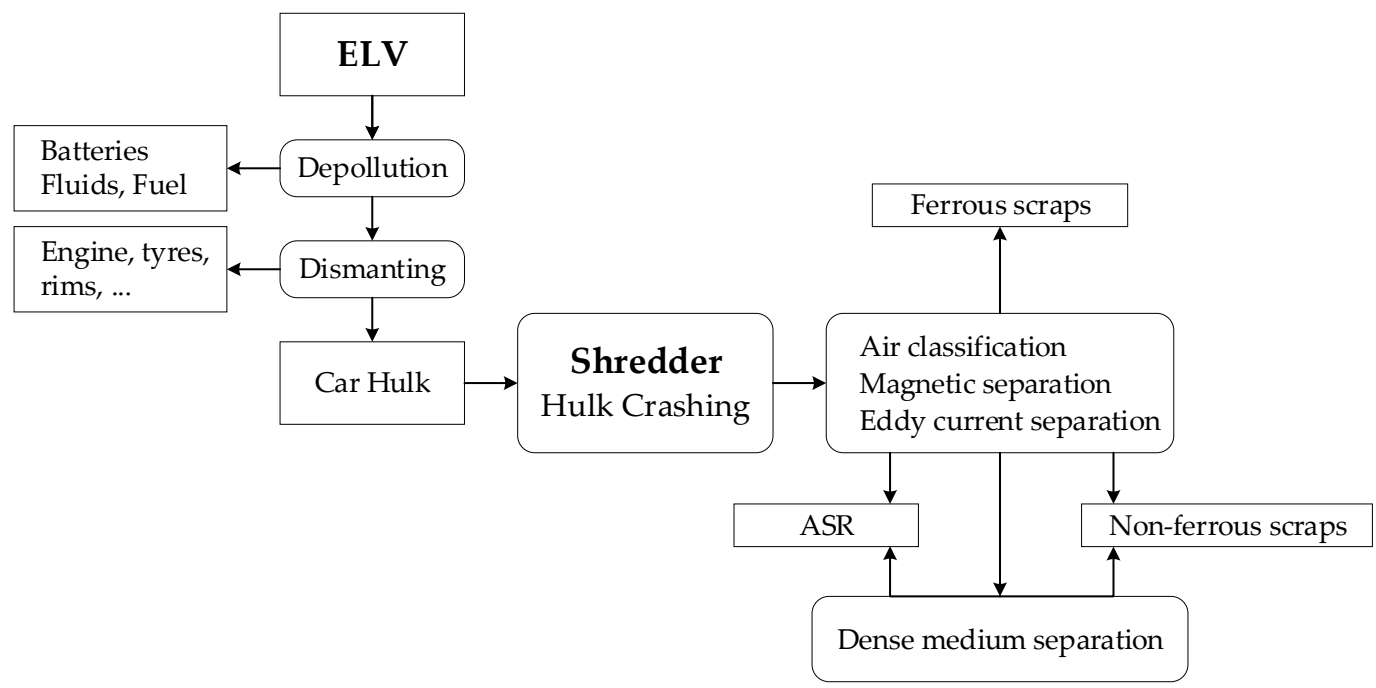

Figure 2. Recycling process of ELVs.

With the increase of polymer utilization, the residual fraction of ASR is expected to increase in the future. Due to their high heterogeneity and hazardous ingredients, ASRs are nowadays commonly disposed of in landfill sites. ASRs contain more than $60 \%$ of the total weight of plastics and elastomers. Figure 3 shows the ingredients of ASRs as referred to in different studies $[1,2,5,11,15,20]$. 


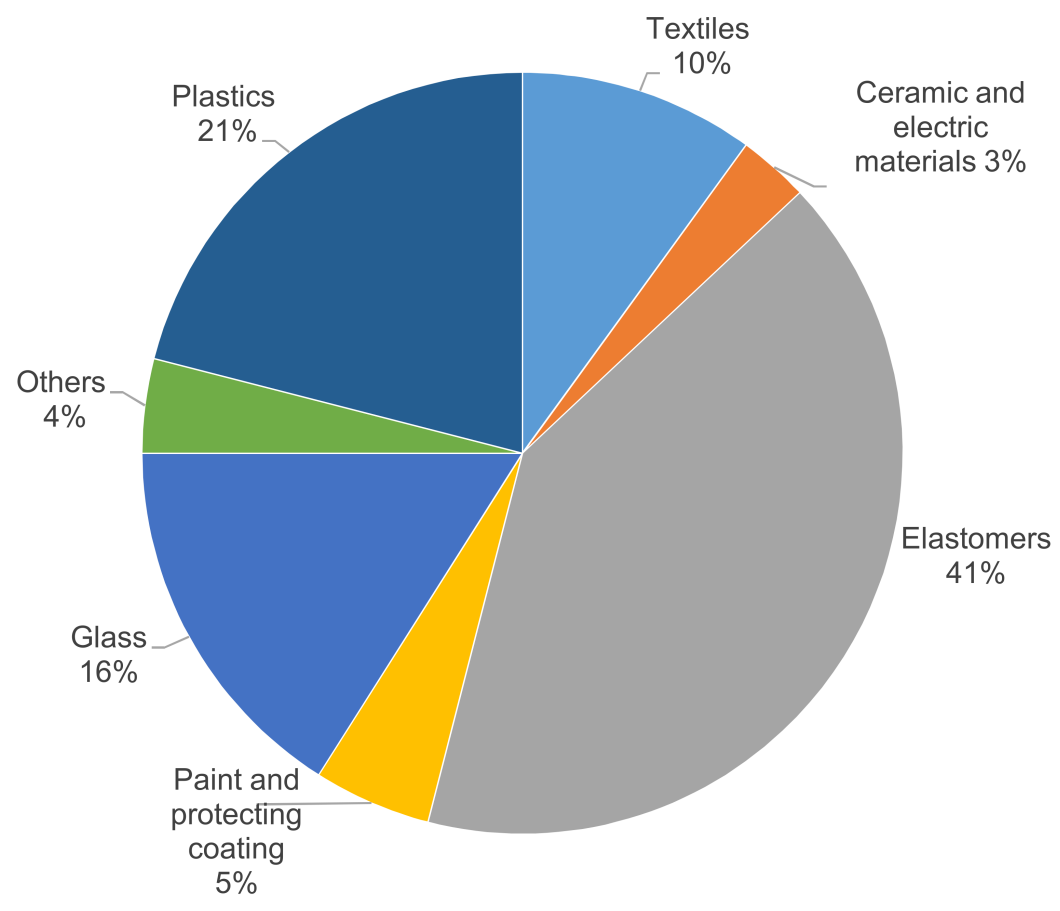

Figure 3. Ingredients of ASRs.

ASRs contain many types of pollutants such as heavy metals and chlorine. Therefore, thermal recovery processes like pyrolysis, gasification, and incineration could bring new risks to the environment. The main automotive industry countries have created legislation for the material recycling of ELVs and ASRs. The EU Directives 2000/532/EC, 2001/18/EC2, 2001/119/EC3, and 2001/573/EC4 regulate that from the beginning of January 2015, ELVs should achieve a comprehensive recovery rate of $95 \%$ (weight), among which the recycling rate for secondary raw material must achieve $85 \%$ (mass) within the EU countries.

In China, the National Development and Reform Commission Proclamation 2006/9 also regulated that the recovery rate of ELVs needed to reach at least $95 \%$ by 2017, among which the recycling and reuse rate for secondary raw materials must represent at least $85 \%$. In order to fulfill the requirements of these directives, the recycling of ASRs is the only effective method. Polymers occupy the greatest proportion of ASR ingredients and have stable properties against aging and corrosion, which are appropriate for producing secondary raw materials [1,4,5,20].

Currently available post-shredding-technologies (PSTs) could realize the recycling of metallic, woody, and glass materials. The only technique which is effective for the separation of polymers is the sink-flotation method. However, this can only sort the ASR polymers into different mixtures with corresponding ranges of densities (specific gravities), as shown in Figure $4[17,18,20,21]$.

Figure 4 shows that although some types of ASR polymers are significantly concentrated in a specific range of densities, like PP in the range of $<1 \mathrm{~g} / \mathrm{m}^{3}$, ABS in the range of $1.05-1.1 \mathrm{~g} / \mathrm{m}^{3}$, and rubber in the range of $1.15-1.2 \mathrm{~g} / \mathrm{m}^{3}$, the sorting products are still mixtures of several materials. In fact, the only successfully sorted pure material is PVC, which has a specific density of more than $2 \mathrm{~g} / \mathrm{m}^{3}$.

The incomplete sorting of ASR polymers still limits their utilization as secondary raw materials. Although there have been some examples of successful implementation like the VW-SiCON process, R-Plus process, etc., none of these technologies has realized yet the material regeneration of ASR polymers. Hence, novel methods and technologies using corresponding force fields (gravity, magnetic, etc.) that are independent of traditional methods urgently need to be developed to produce secondary raw polymer materials with high purities $[1,5,10,18,21]$. 


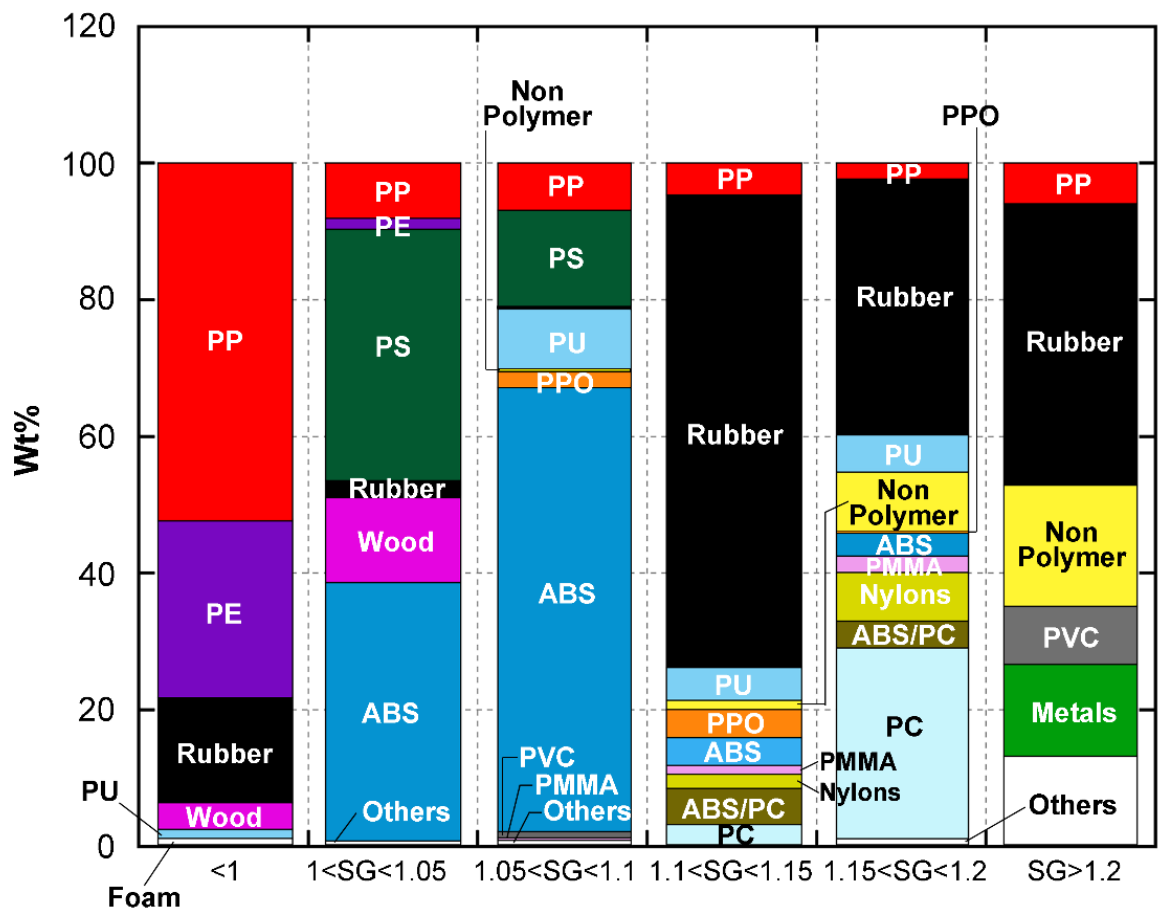

Specific Gravity

Figure 4. Flotation separation of ASR polymers.

Since the last decade, a new kind of material recognition and sorting mechanism by using modern sensor technologies, which are generally called sensor aided/based sorting (SAS/SBS) methods, has been rapidly developed. This mechanism is defined as single grain separation by using the contact-free detection of externally identifiable and measurable feature parameters. With the principles of SBS, several kinds of polymer recognition and sorting methods have been developed such as visual sorting, near infrared (NIR) and middle infrared (MIR) sorting, tribo-electrification sorting, etc. However, these principles are still unusable for ASR polymer mixtures. Visual sorters are only available for color detection, not for homochromatic features, and more than $95 \%$ of vehicle polymer materials are black; the NIR spectral analysis method is able to recognize most kinds of polymers with adequate precision, but it is unavailable for black and darkly dyed polymers, which absorb nearly $100 \%$ of NIR irradiation and result in inadequate reflection. The MIR spectral method can make sufficient reflected signals on the surface of black polymers, but it needs a very long irradiation time (several minutes), which strictly limits its industrial utilization. Furthermore, vehicle plastics are always modified and reinforced by padding with different additive agents like talc, carbon black, etc. These additives have a serious influence on the tribo-electrification properties of polymers [3,10,18,20-22].

In the last decade, sensor-based sorting by using microwave induced thermal imaging has been developed and implemented in sorting materials with microwave sensitivity. Microwaves are electromagnetic waves in a frequency range of $300 \mathrm{MHz}$ to $300 \mathrm{GHz}$, which are always divided into several bands (S, X-band, etc.). S-band microwave radiation has been proven to be able to heat dielectric materials rapidly and homogeneously from the inside to outside as the sensitive parts to microwave irradiation are the polar molecules of materials. Several companies have developed vehicle elastomer and foam part production technology using microwave irradiation [23-28].

With the different molecular arrangements and structures of polymers, the heating effects are also different, which leads to temperature variations in irradiated materials. Particularly polar molecules, i.e., the additive agents used for the modification and reinforcement of polymers are very sensitive to microwaves, and can directly demonstrate the corresponding heating effect distributions, which 
could be utilized for the classification of specific kinds of materials $[23,26,29,30]$. With modern thermal imaging technology, the heating effect on polymers can be detected with high precision.

Microwaves heat materials that contain specific concentrations of polar molecules: when the dielectric of the polar molecules is placed in the microwave electromagnetic field, a dipole or an existing dipole rearrangement will be formed in the dielectric material. In the high-frequency alternative electromagnetic field, the movement orientations vary with a frequency of billions of times per second, which leads to strenuous movements and collisions between the polar molecules, which further cause a "stirring" effect at the molecular level [26,31,32]. This effect results in the generation of large amounts of heat which can achieve the direct conversion of electrical energy to inner heat. The thermal energy in the medium increases the temperature of the materials, and it can be seen that the microwave heat comes from the loss of electric field energy inside dielectric material [33]. Vehicle polymers consist of different kinds of elastomers and plastics, which are significantly different in polarity. This difference of polarities can be used for the sorting and separation criteria of ASR polymers. The difference of material polarities can be deduced by variations in the microwave heating effect, which can be easily acquired through modern infrared imaging technology $[34,35]$.

In this research, we studied a novel method using S-band microwave irradiation together with 3D imaging as well as thermal imaging sensors to recognize and sort the plastic and elastomer materials in ASR mixtures. In this study, an industrial microwave emitter array with $2.45 \mathrm{GHz} / 9 \mathrm{~kW}$ was utilized as the irradiation source. Seven kinds of vehicle polymer materials were tested: three kinds of plastics: polypropylene (PP), polyvinyl chloride (PVC), and acrylonitrile butadiene styrene (ABS); and four kinds of elastomers: styrene butadiene rubber (SBR), chloroprene rubber (CR), nitrile butadiene rubber (NBR), and ethylene-propylene-diene monomer (EPDM).

\section{Materials and Methods}

\subsection{Principle of Microwave Heating}

Microwave irradiation can be reflected, absorbed, or penetrate the surfaces of materials and has nearly no energy loss in transmitting insulators. Conductors such as metals can reflect microwaves and result in no transmission. Water, metal oxides, and carbon-based materials can cause high energy loss during transmission, and these kinds of materials are called dielectric materials [23-26].

The mechanism of microwave field energy loss caused by transmission in dielectric materials is as follows: in an alternative electromagnetic field, polarization appears in dielectric molecules where the dipole and interfacial polarization time is about $10^{-9}-10^{-12} \mathrm{~s}$. This period coincides with the frequency domain of microwaves, which cause the molecule polarization movements which lag behind the frequency change of the alternating electromagnetic field, and further lead to the dielectric loss of microwave energy. The dielectric properties of materials determine their energy absorption, i.e., the heating effects under microwave irradiations, which can be described by using complex permittivity $\varepsilon$ as [31,33]:

$$
\begin{gathered}
\varepsilon=\varepsilon_{0} \varepsilon_{r}=\varepsilon_{0}\left(\varepsilon_{r}^{\prime}-i \varepsilon_{r}^{\prime \prime}\right) \\
\tan \delta=\frac{\varepsilon_{r}^{\prime \prime}}{\varepsilon_{r}^{\prime}}
\end{gathered}
$$

where $\varepsilon_{0}$ is the vacuum permittivity with a constant value of $8.854 \times 10^{-12} \mathrm{~F} / \mathrm{m}$. $\varepsilon_{r}$ is the complex permittivity where $\varepsilon_{r}^{\prime}$ is its real part, and represents the dielectric energy storage capacity through material molecule polarization. $\varepsilon_{r}^{\prime \prime}$ is the imaginary part, which represents the loss of electromagnetic energy inside the materials. $\tan \delta$ is the tangent of the energy loss angle, which indicates the ratio of microwave energy loss to energy stored in the molecules' polarization. Most of the commonly used materials have a very small value of vacuum permittivity, normally we use $\varepsilon_{r}$ and $\tan \delta$ to describe the materials' dielectric properties. 
The electromagnetic energy loss due to the dielectric properties is absorbed by the materials and finally results in an increase in temperature. Polymers including plastics and elastomers are mostly insensitive to microwave irradiation, but the polymers used to produce vehicle parts are always modified or reinforced for better mechanical properties. The additive agents used for modification are carbon-based or mineral materials, which are specifically formulated for the corresponding polymer and are highly sensitive to microwaves. Therefore, we can distinguish different vehicle polymers by detecting their heating effects under microwave irradiations since different kinds of polymers have different modification and reinforcement formulations. The direct measurement of $\tan \delta$ is hard since it is very difficult to measure the energy loss of microwaves before and after transmission in materials. However, the effect of $\tan \delta$, i.e., the temperature increase, can be easily measured by using modern sensor technologies such as infrared thermal imaging cameras.

Microwave heating efficiency can be described by using the average power absorption density $P_{d}$ as [33]:

$$
P_{d}(z)=\frac{\omega}{c} \times \frac{4 \varepsilon_{r}^{\prime \prime} S_{0} e^{-2 \alpha z}}{\sqrt{\varepsilon_{r}^{\prime 2}+\varepsilon_{r}^{\prime \prime 2}}+\sqrt{2\left(\sqrt{\varepsilon_{r}^{\prime 2}+\varepsilon_{r}^{\prime \prime 2}}+\varepsilon_{r}^{\prime}\right)+1}}
$$

where $S_{0}$ is the average power density of microwave irradiation; $c$ is the vacuum light velocity; $\omega$ is the angular frequency of microwave; $\alpha$ is the microwave attenuation coefficient; and $z$ is the transmission depth of microwave. According to Equation (3), the transmission thickness of the tested object can have an influence on heating homogeneity. However, as related studies have pointed out, for normal dielectric polymer materials, with a transmission thickness less than $10 \mathrm{~mm}$ and an irradiation power larger than $9 \mathrm{~kW}$ as well as an irradiation time of less than $30 \mathrm{~s}$, the heterogeneity of temperature increasing from the inside to the surface is always less than $0.1{ }^{\circ} \mathrm{C}$, which can be ignored for the purposes of this study. All of the tested polymer scraps came from crushed vehicle parts; due to the purpose of vehicle lightening, most vehicle parts had a hollow structure with a small thickness. Hence after crushing, the scraps had a flaky structure with thicknesses around 3-8 $\mathrm{mm}$. Polymer recognition by detecting the heating effect of microwaves on flaky scraps was appropriate for our research.

\subsection{Experimental Facility Installation}

In our research, an industrial conveyor microwave facility with a frequency of $2.45 \mathrm{GHz}$ (wavelengths of approximately $12 \mathrm{~cm}$ ) was used. This frequency corresponds to the most utilized heating frequency in the S-band. The conveyor microwave facility was set up by the company Media ${ }^{\odot}$ in December 2016 for our research. This facility has a $2 \mathrm{~m}$ long chamber which is completely surrounded by stainless steel to confine all the irradiation inside the chamber. Its interior walls are porous; below the conveyor belt, ceramic plates were installed to absorb the reflected microwave radiation from the stainless-steel wall.

Above the inner conveyor, there are six magnetrons with a frequency of $2.45 \mathrm{GHz}$ installed on the top of the microwave chamber in one row. In this research, we used three magnetrons. Each magnetron had a maximum output of $3 \mathrm{~kW}$ that could be varied in $1 \mathrm{w}$ increments. The maximum capacity of the microwave radiation was $9 \mathrm{~kW}$, and the homogeneity of microwave irradiation was insured by the facility supplier.

The conveyor belt was made of a beige textile with a width of $50 \mathrm{~cm}$. This textile ensured that the conveyor belt would not be heated within an irradiation period of several hours. The velocity of the conveyor belt could be adjusted from $0.2 \mathrm{~m} / \mathrm{s}$ to $2 \mathrm{~m} / \mathrm{s}$, with an increment of $0.1 \mathrm{~m} / \mathrm{s}$ to be varied. The whole installation of the facility and the tests of the polymer scraps are shown in Figure 5.

In this research, the velocity of the conveyor belt was set at $0.2 \mathrm{~m} / \mathrm{s}$, therefore the tested scraps were irradiated in microwave field for $10 \mathrm{~s}$. 

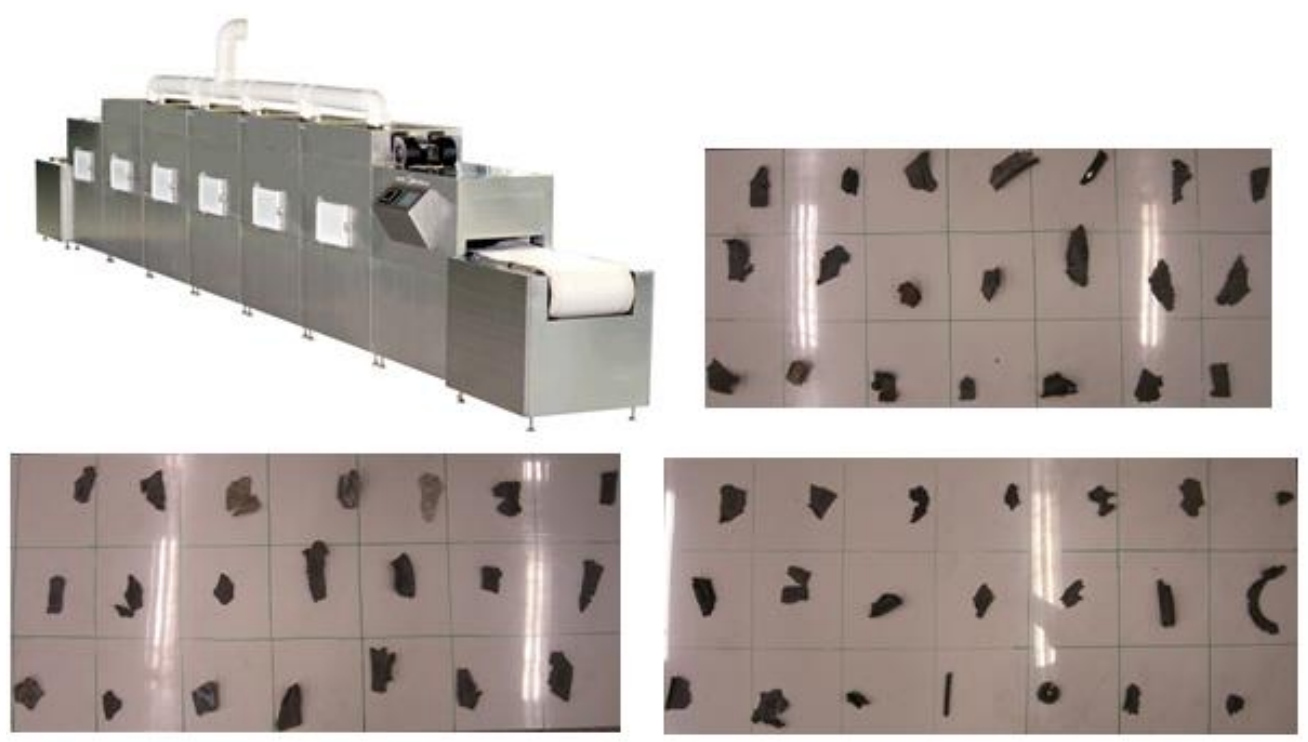

Figure 5. Installation of conveyor microwave facility and the tests of polymer scraps.

\subsection{Sensor System Installation}

The sensor system was composed of a thermal imaging infrared camera and a 3D line scan camera together with a laser-triangulation setting. The design and installation of the sensor system is shown in Figure 6.

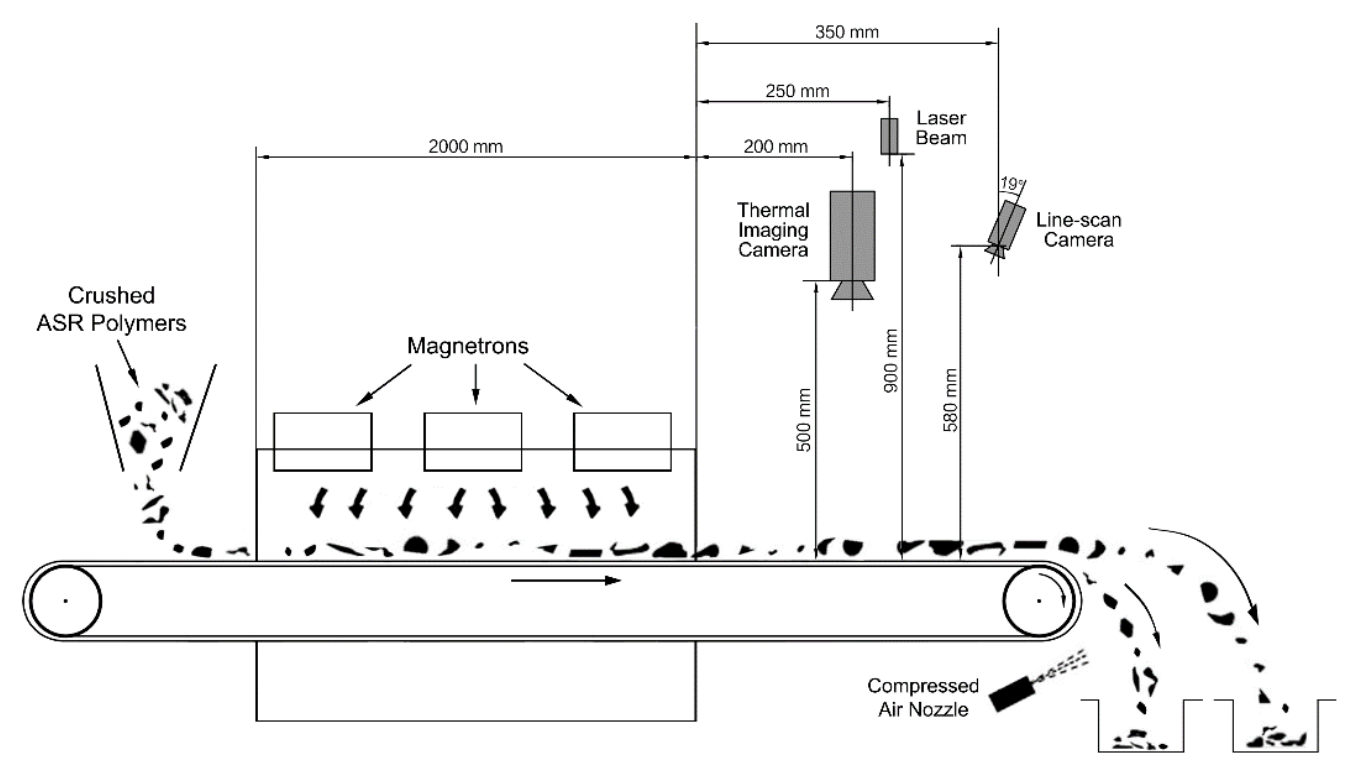

Figure 6. Installation of the sensor system on the conveyor microwave facility.

All the crushed ASR polymer scraps were designed to be dropped onto the conveyor individually by the vibration feeder, then they were carried to pass through the microwave irradiated area where they were heated. Above the exit of the microwave chamber, two sensors were installed to acquire the features of the tested scraps, then at the end of the conveyor, the recognized object scraps were sorted by compressed air separation from the main scrap stream.

The thermal infrared camera captured the temperature information of the single polymer scraps and saved them in a grayscale graph. By using this method, it was possible to acquire any pixel of temperature in the thermal images [34,35]. The infrared camera was a line scan camera with the model 
of "pyroline 128 ls $/ 512 \mathrm{~Hz}$ " from the company DIAS Co. Ltd. (Dublin, Ireland), which is available for the temperature range of 0 to $80^{\circ} \mathrm{C}$ with a resolution of $0.1{ }^{\circ} \mathrm{C}$. The measurement uncertainly of this infrared camera was $\sigma=0.01 \times \mathrm{T}^{\circ} \mathrm{C}$ ( $\mathrm{T}$ is the ambient temperature). The infrared camera had its $\mathrm{CCD}$ sensor in 128 pixels. Its properties were enough for the acquisition of the heating effect. The other information for positioning and image mask generation of the tested scraps were realized with the help of 3D scan sensor.

The 3D line scan camera was the optical sensor used to acquire the position and geometrical features of the tested scraps and provide masks that could be used to cover the thermal image for locating the tested scraps. The scrap positions acquired by this sensor were used to control the air nozzle to blast the corresponding scraps out of the main material stream.

The acquisition of the height information of the tested scraps was realized by the mechanism of 3D laser triangulation. The mechanism of the 3D camera triangulation measurement is shown in Figure 7. In Figure 7, $O$ and $P$ represent the focal point of the 3D scan camera and the position of the laser beam, respectively. In this research, we used only one laser beam to be emitted vertically to the conveying direction. $h_{1}$ and $h_{2}$ represent the heights of the 3D scan camera and laser beam, respectively. The height of a scrap's surface point $W$ could be set with $h$. The horizontal distance of the conveyor belt between the 3D scan camera and laser beam is $L$, where $L=\overline{O_{1} P_{1}}$. The installation angle between the lens axis and vertical direction is $\alpha_{0}$, and the angle between the line $\overline{O W}$ and the lens axis is $\alpha . \beta_{0}$ is the installation angle between the laser path and vertical direction, and $\Delta \beta$ is the laser path angle between the adjacent laser beams, here we had only one laser beam.

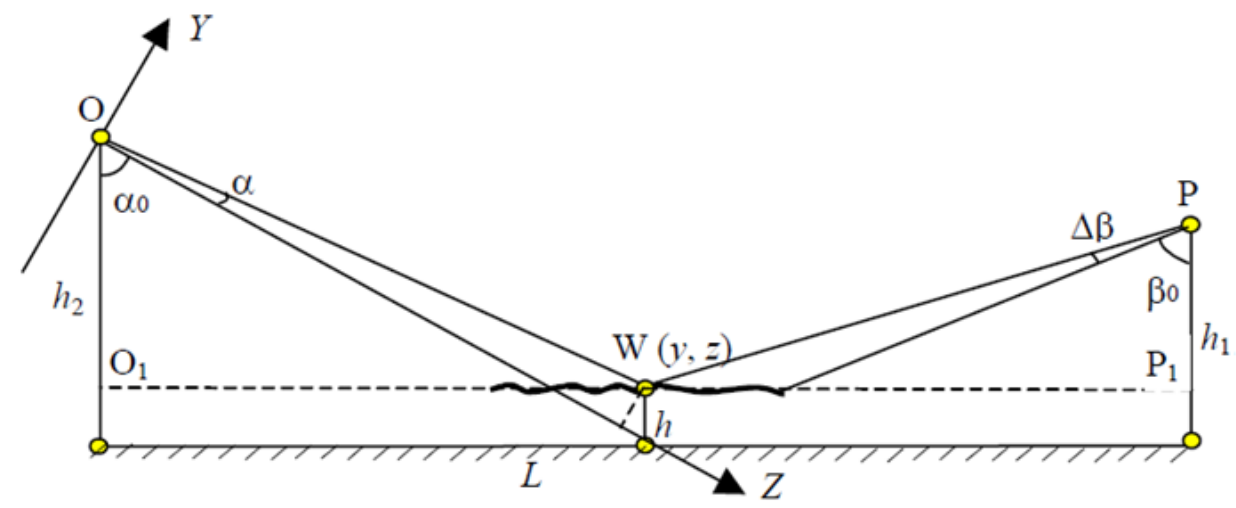

Figure 7. Mechanism of laser triangulation scanning.

The installation of the scan camera, the laser beam, and the tested objects formed triangle structures, which constitute the 3D-laser-triangulation measurement. The laser beams were photographed with different grayscales by the line scan camera according to the height of the tested scrap surface, i.e., the distance between the camera lens and scrap surface. The distance $L$ is known, the setting angles $\alpha_{0}$ and $\beta_{0}$ are also given, and the angle $\alpha$ could be determined by focusing on the strike point of the laser beam. These geometrical parameters determined the size of a scrap triangle and gave its position. The imaging of the laser triangulation on the camera sensor is shown in Figure 8. 


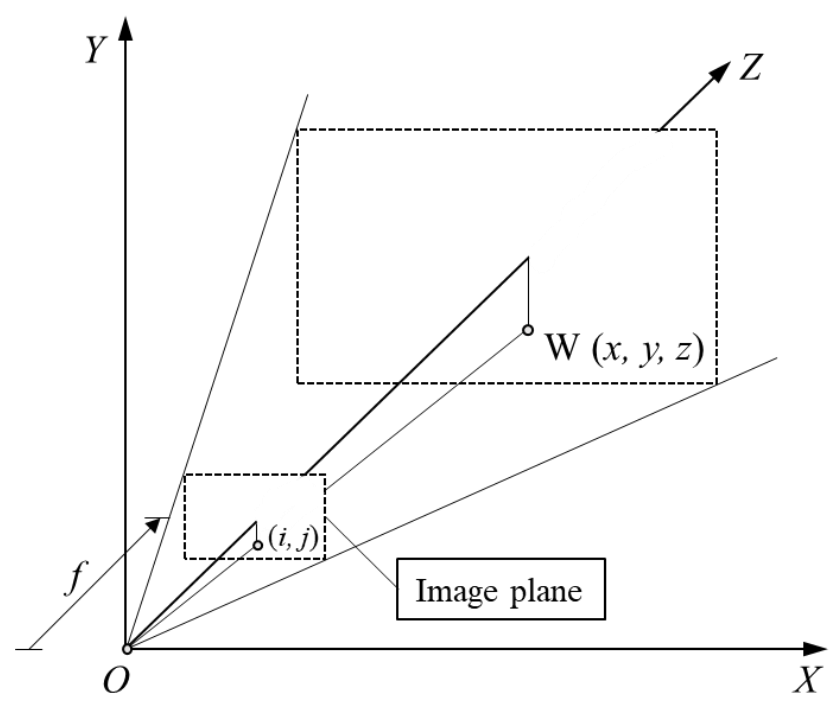

Figure 8. CCD imaging mechanism.

If $f$ is the focal length of the camera and $(i, j)$ is the pixel in the image plane that corresponds to a point $W(x, y, z)$ on the specimen surface, then two similar triangles give the following equation:

$$
\frac{y}{j}=\frac{z}{f}
$$

According to the laser triangulation mechanism and the triangles $\triangle O O_{1} \mathrm{~W}$ and $\triangle P P_{1} W$, the following equation can be obtained:

$$
h=\frac{\left[L-h_{1} \tan (\beta+\Delta \beta)\right]\left(f-j \tan \alpha_{0}\right)-\left(j-f \tan \alpha_{0}\right) h_{2}}{\left(f-j \tan \alpha_{0}\right) \tan (\beta+\Delta \beta)+f \tan \alpha_{0}+j}
$$

where the focal length of the 3D line scan camera is $f$ and $(i, j)$ is the pixel in the imaging area that corresponds to the point $W(x, y, z)$ on the tested scrap. In Equation (2), only $j$ is a variable that needs to be determined by the camera sensor. All the other parameters are given through the system structure. In this research, only one laser beam was utilized and set to irradiate vertically on the conveyor belt, hence the angles $\beta_{0}$ and $\Delta \beta$ were zero. Then, Equation (2) can be rewritten as:

$$
h=\frac{L\left(f-j \tan \alpha_{0}\right)-\left(j-f \tan \alpha_{0}\right) h_{2}}{f \tan \alpha_{0}+j}
$$

Equation (3) describes the measurement of the height information of the tested scraps, which could be combined with the shape and position features that are also acquired by the 3D line scan camera to generate the mask image. Masks were used to cover the thermal image in order to determine the useful area where the heated polymer scraps were presented.

The 3D line scan camera was an AT C3-1280-CL (BASLER, Ahrensburg, Germany) 16-bit line scan camera with a highest scan frequency of 47,000 lines/s and a resolution of 1280 pixels. The laser beam used for the 3D measurements was monochromic, with a wavelength of $660 \mathrm{~nm}$.

\subsection{Implemented ASR Polymer Materials in This Research}

The ASR polymer materials came from diverse parts such as bumpers, side bumper slides, dashboards, fuel tanks, pipes, sealing elements, fenders, pedals, inner decorations, exterior parts, etc. In this research, the tested ASR polymers were sampled from a vehicle recycling facility located near the city of Nanjing. Due to the number of polymers utilized in vehicles, we sampled seven of the most commonly found materials directly from ELVs, including four kinds of elastomers: styrene butadiene 
rubber (SBR), chloroprene rubber (CR), nitrile butadiene rubber (NBR), and ethylene-propylene-diene monomer (EPDM); and three kinds of plastics: polypropylene (PP), polyvinyl chloride (PVC), and acrylonitrile butadiene styrene (ABS). All of the parts that belonged to those materials in single ELVs were sampled. The usage of tire rubber is normally much more than these kinds of polymers, but the tires are usually disassembled before being crushed as part of another recycling process. Tire rubber is rarely found in crushed ASRs. The absolute amount of PVC is normally minor in ASR mixtures, but due to its high toxicity to the environment, PVC must be removed as much as possible before landfilling. Therefore, PVC was also studied in this research.

Some of the vehicles were used for much longer than their legal lifetime. Hence, we sampled the seven kinds of materials from ELVs that were manufactured during two periods: 2000-2005 and 2006-2010, respectively. The average usage time of the ELVs was 12.7 years. The sample information is shown in Table 1.

Table 1. Sampling of ASR polymers for research on domestic and foreign vehicles.

\begin{tabular}{|c|c|c|c|c|}
\hline \multirow{2}{*}{$\begin{array}{l}\text { Polymer } \\
\text { Varieties }\end{array}$} & \multicolumn{2}{|r|}{ 2000-2005 Produced } & \multicolumn{2}{|r|}{ 2006-2010 Produced } \\
\hline & $\begin{array}{l}\text { Per Car } \\
\text { Usage/kg }\end{array}$ & Sampling Parts from ELVs & $\begin{array}{l}\text { Per Car } \\
\text { Usage/kg }\end{array}$ & Sampling Parts from ELVs \\
\hline SBR & 48.22 & $\begin{array}{l}\text { Tires, shock absorption products, } \\
\text { water pipes, brake hoses, cups }\end{array}$ & 42.06 & $\begin{array}{c}\text { Tires, shock absorption products, } \\
\text { metal seal ring of electrical } \\
\text { components, water pipes, brake } \\
\text { hoses, cups }\end{array}$ \\
\hline $\mathrm{CR}$ & 5.69 & $\begin{array}{l}\text { Hoses, dust cover, wiper, fan belt, } \\
\text { synchronous belt }\end{array}$ & 3.81 & $\begin{array}{l}\text { Hoses, dust cover, wiper, fan belt, } \\
\text { synchronous belt }\end{array}$ \\
\hline NBR & 8.64 & $\begin{array}{l}\text { Oil filler pipe, fuel pipe, flow } \\
\text { control hose, oil seal, film pieces }\end{array}$ & 4.28 & $\begin{array}{l}\text { Oil filler pipe, fuel pipe, flow } \\
\text { control hose, oil seal, film pieces }\end{array}$ \\
\hline EPDM & 14.29 & Heater pipes, sealing strip, cables & 16.46 & Heater pipes, sealing strip, cables \\
\hline PP & 22.34 & $\begin{array}{l}\text { Bumpers, dashboards, lightings, } \\
\text { panels, bonnets }\end{array}$ & 31.45 & $\begin{array}{l}\text { Bumpers, dashboards, pedals, } \\
\text { inner decoration }\end{array}$ \\
\hline PVC & 4.22 & $\begin{array}{l}\text { Exterior trim, cables, Upholstery, } \\
\text { Electrical components }\end{array}$ & 2.12 & Cables, Electrical components \\
\hline ABS & 11.28 & $\begin{array}{l}\text { Seats, Cockpits, Interior trims, } \\
\text { Exterior trims, lightings }\end{array}$ & 12.38 & $\begin{array}{l}\text { Seats, lightings, bumper slides, } \\
\text { trims }\end{array}$ \\
\hline
\end{tabular}

Generally, there was no significant difference in either the absolute amounts or the proportional usages. Imported vehicles always utilize more engineering plastics than domestic vehicles. The seven kinds of typical materials accounted for more than $85 \%$ of the total polymer materials in ELVs. After crushing with a hammer mill, the particle size distribution of these scraps was $4-22 \mathrm{~mm}$, and their thicknesses covered a range of 2.5-8.7 mm. The total mass of sample material utilized for this research was PVC $5.12 \mathrm{~kg}$, ABS $4.78 \mathrm{~kg}$, PP $4.36 \mathrm{~kg}$, EPDM $5.77 \mathrm{~kg}$, NBR $6.45 \mathrm{~kg}$, CR $6.32 \mathrm{~kg}$, and SBR $6.68 \mathrm{~kg}$, respectively. All the tested samples had a water content of less than $1 \%$.

\section{Results and Discussion}

In the experiments, according to the research purposes there were two approaches. In the first approach, the heating temperature of the different material scraps was determined. In the second approach, the corresponding material scraps were sorted by using the variations of their heating temperature features. All of the results are introduced in the following subsections.

\subsection{Determination of Heating Effects}

The ambient temperature when the experiments were implemented was $18.5-27.5^{\circ} \mathrm{C}$. Before each experiment, the ambient temperature was measured as the basic temperature of the tested scraps and the lower threshold of the infrared imaging camera. All of the polymer scraps were tested to pass through the microwave irradiation field three times with the irradiation power of $3 \mathrm{~kW}, 6 \mathrm{~kW}$, 
and $9 \mathrm{~kW}$, respectively. The velocity of the conveyor belt was $0.2 \mathrm{~m} / \mathrm{s}$ for all tests, i.e., the irradiation time was $10 \mathrm{~s}$ for all tested scraps. The temperatures of the heated scraps were acquired online by the infrared imaging camera. Figure 9 shows a pseudo-colored image of the microwave heating effect on a pixel scale on very small tested particles.

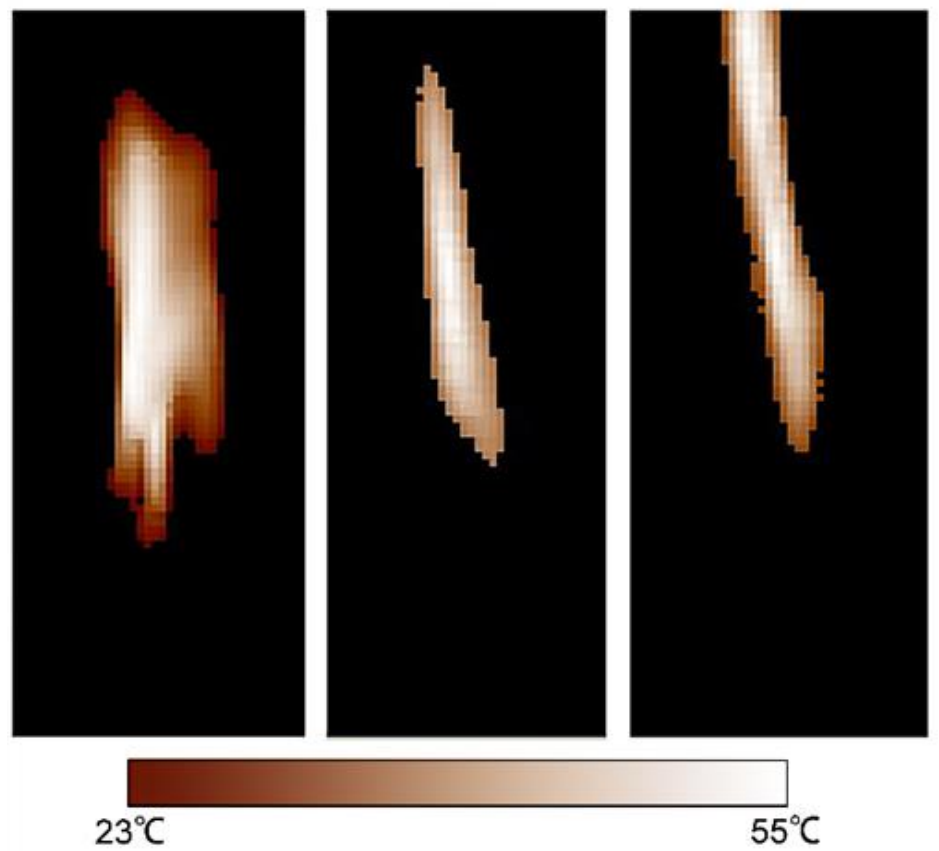

Figure 9. Pseudo-coloring of temperature infrared images.

Figure 9 demonstrates the heating effect distribution on tested polymer scraps from pixel to pixel in pseudo-coloring, where the original image was illustrated in grayscale. A lighter color indicates a higher temperature. The pseudo color images obviously showed that the differences of temperature increase in different polymer materials. It was found that on the edges of the scraps, the temperatures were lower than in the middle of the scraps. The reason was that because the size of these scraps was too small (less than $5 \mathrm{~mm}$ ), when they came out of the irradiation chamber, they were rapidly cooled down. Additionally, the infrared camera had to be placed at least $200 \mathrm{~mm}$ away from the exit of the microwave chamber to avoid the interference from microwave radiation on the infrared sensor. Therefore, the tested scraps needed to have relatively larger particle sizes. In this research, by using appropriate crushing velocities, we kept 95\% (by mass) of the tested polymer scraps with particle sizes larger than $30 \mathrm{~mm}$.

The infrared thermal imaging sensor could only record the temperature of its whole viewing area. In order to determine the interesting areas where the tested scraps lay on the conveyor, we used the 3D line scan camera to produce masks for the thermal images where the corresponding area of the tested scraps were illustrated using a binary mask image. This process is shown in Figure 10.

In the raw 3D line scan image, the height of the surface on which the laser beam actually stroked was illustrated with different grayscales. This grayscale image was 16-bit, which means that in each pixel, there were $2^{16}$ different grayscale values to describe the height of the scraps. Here, we selected the surface of the conveyor belt as the lower threshold plane of the grayscales, and then set all the grayscales, which were larger than the threshold, as equal to 1 (white), meaning the area with heights larger than the surface of conveyor belt i.e., the area of scraps. Grayscale values equal to/smaller than this threshold were set at 0 (black), which meant the area without the tested scraps. Therefore, we obtained a binary image of the 3D scan image, i.e., the position and geometrical area features of the tested scraps. This binary image was the mask image for the infrared thermal image. 


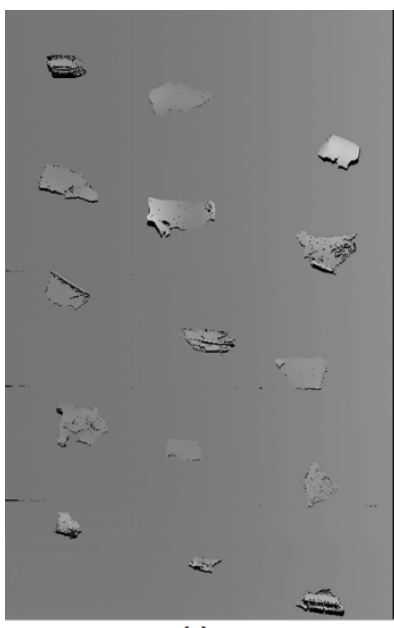

(a)

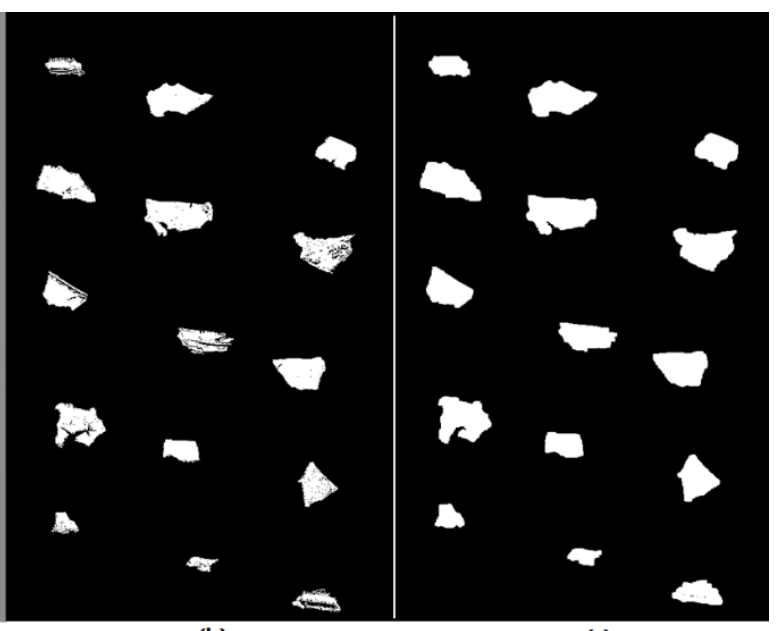

(b)

(c)

Figure 10. Process for producing of mask for infrared thermal images: (a) 3D scan grayscale image; (b) binary image of 3D scan image; and (c) prepared mask for infrared thermal image.

As all of the tested scraps were black or dark dyed, therefore, some of their surfaces could not generate an adequate reflection of the laser beam and further caused black spots inside the classified object area on the binary image. Hence, we added more processing by using erosion algorithms to eliminate these spots inside the scrap areas, as illustrated in Figure 10c.

By using the mask image, the corresponding areas on the thermal image that described the temperature information of the tested scraps could be segmented for further analysis. This process is shown by one test on an example material in Figure 11.

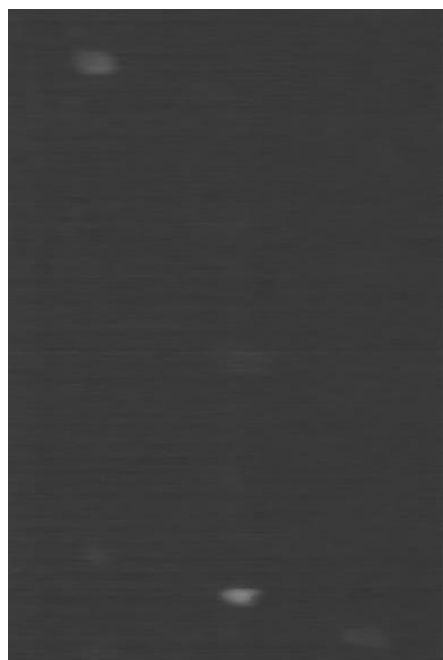

(a)

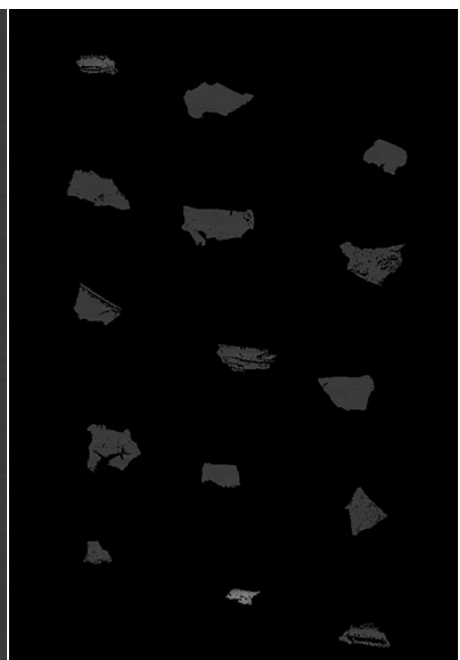

(b)

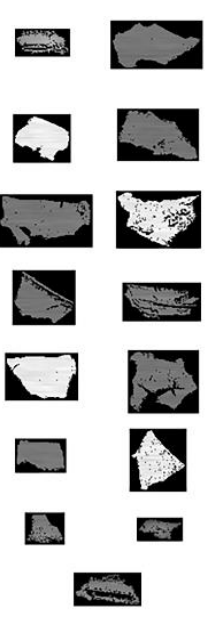

(c)

Figure 11. Temperature information acquisition from infrared thermal image: (a) original thermal image; (b) mask on the thermal image; and (c) segmented area of object scraps of thermal image.

Figure 11 shows that, from the raw infrared thermal image, it was very difficult to determine the area of the tested objects, especially when their temperature increases were not significant and could not be distinguished by the human eye. With the help of the binary mask image, as shown in Figure $11 \mathrm{~b}$, the interesting areas where the tested scraps were located were easily determined and then the object areas were segmented from the thermal image for temperature feature extraction. In fact, 
the interesting areas were segmented according to their edges on the mask, here we had to show them clearly; hence we demonstrate these with a rectangular window in Figure 11c.

The temperature distribution features on the entire surface of the tested polymer scraps acquired by the infrared imaging camera were stored with a 5\% percentile step, then they were analyzed and illustrated with Box-Whisker diagrams. In this diagram, the distribution of the acquired temperature data was illustrated with the minimal and maximum values and the $25 \%, 50 \%$, and $75 \%$ percentiles. Of course, the percentiles could also be set arbitrarily from 1-100\% according to the different data mining requirements.

\subsection{Microwave Heating Effect on Tested Materials}

The temperature rising features of the tested ELV polymer scraps including PVC, ABS, PP, EPDM, NBR, CR, and SBR under the irradiation power of $3 \mathrm{~kW}$, respectively, are shown in Figure 12 as follows:

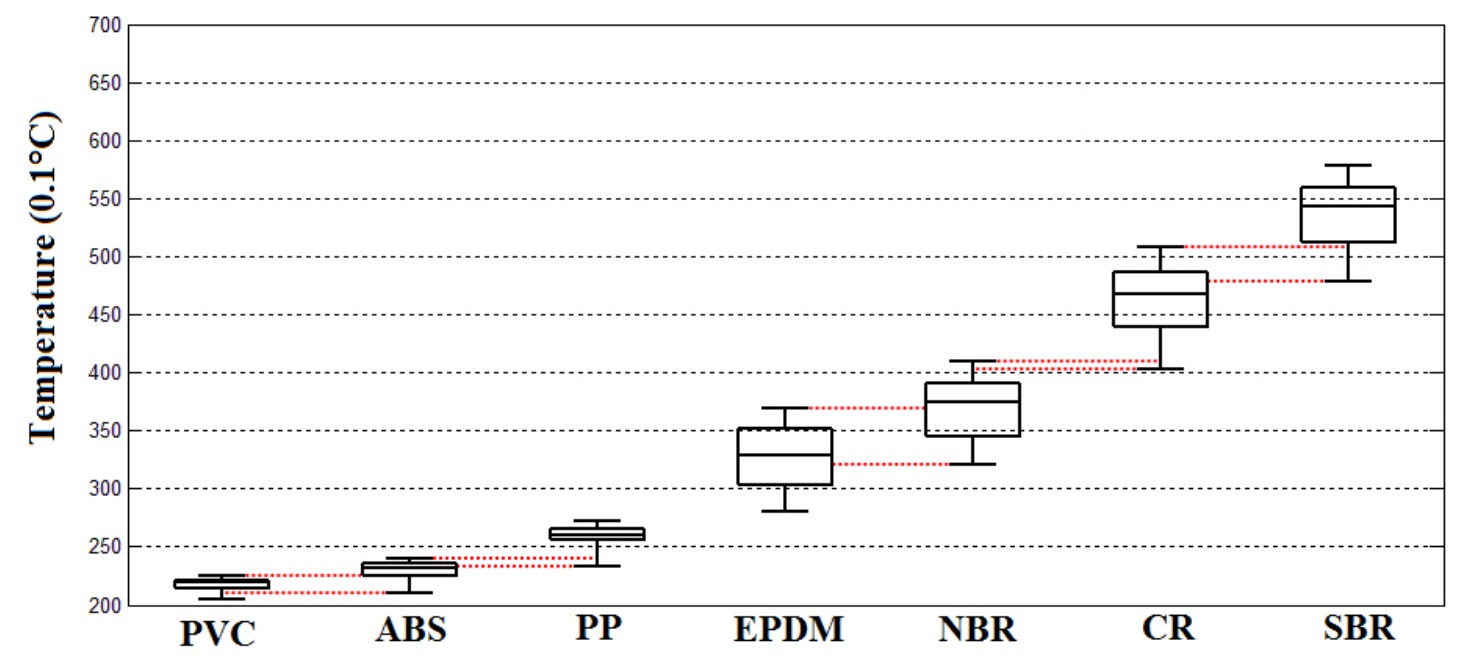

Figure 12. Distribution of temperature rises of the tested polymer samples under a microwave irradiation power of $3 \mathrm{~kW}$.

The ambient temperature when this experiment was implemented was about $19.5^{\circ} \mathrm{C}$ with a $3 \mathrm{~kW}$ microwave irradiation of $10 \mathrm{~s}$. The temperature distribution features of tested scraps were:

- The temperature distribution of the PVC scraps was $20.5-22.5^{\circ} \mathrm{C}$, the $25 \%$ percentile was about $21.5^{\circ} \mathrm{C}$, the $75 \%$ percentile was about $22^{\circ} \mathrm{C}$, and the median temperature was about $21.8^{\circ} \mathrm{C}$.

- The temperature distribution of the ABS scraps was $22-24{ }^{\circ} \mathrm{C}$, the $25 \%$ percentile was about $22.4{ }^{\circ} \mathrm{C}$, the $75 \%$ percentile was about $23.5^{\circ} \mathrm{C}$, and the median temperature was about $23^{\circ} \mathrm{C}$.

- The temperature distribution of the PP scraps was $23.3-27.2^{\circ} \mathrm{C}$, the $25 \%$ percentile was about $25.5^{\circ} \mathrm{C}$, the $75 \%$ percentile was about $26.6^{\circ} \mathrm{C}$, and the median temperature was about $26^{\circ} \mathrm{C}$.

- The temperature distribution of the EPDM scraps was $27.8-37.2{ }^{\circ} \mathrm{C}$, the $25 \%$ percentile was about $30.2{ }^{\circ} \mathrm{C}$, the $75 \%$ percentile was about $35.1{ }^{\circ} \mathrm{C}$, and the median temperature was about $32{ }^{\circ} \mathrm{C}$.

- The temperature distribution of the NBR scraps was $32.2-41.1^{\circ} \mathrm{C}$, the $25 \%$ percentile was about $34.7{ }^{\circ} \mathrm{C}$, the $75 \%$ percentile was about $39.1^{\circ} \mathrm{C}$, and the median temperature was about $37.7^{\circ} \mathrm{C}$.

- The temperature distribution of the CR scraps was $40.2-51{ }^{\circ} \mathrm{C}$, the $25 \%$ percentile was about $44^{\circ} \mathrm{C}$, the $75 \%$ percentile was about $48.8^{\circ} \mathrm{C}$, and the median temperature was about $45.6{ }^{\circ} \mathrm{C}$.

- The temperature distribution of the SBR scraps was $47.6-57.6{ }^{\circ} \mathrm{C}$, the $25 \%$ percentile was about $50.8^{\circ} \mathrm{C}$, the $75 \%$ percentile was about $55.7^{\circ} \mathrm{C}$, and the median temperature was about $52.7^{\circ} \mathrm{C}$.

- The temperature rising effects of the tested ELV polymer scraps of PVC, ABS, PP, EPDM, NBR, CR, and SBR under the irradiation power of 6 kW, respectively, are shown in Figure 13. 


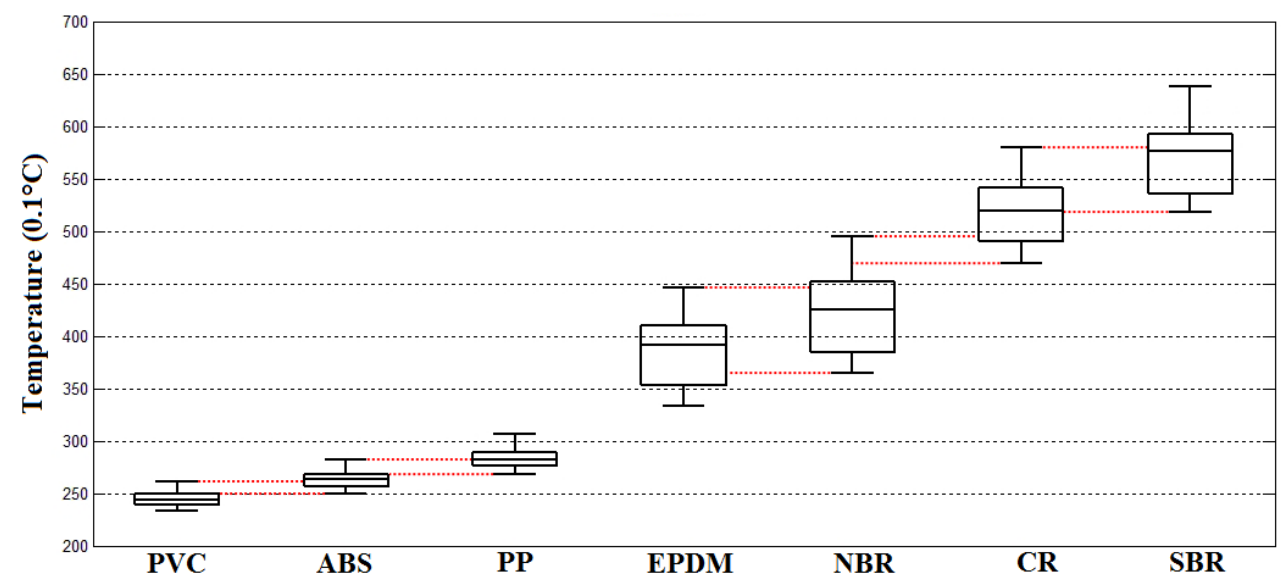

Figure 13. Distribution of temperature rises on tested polymer samples under microwave irradiation power of $6 \mathrm{~kW}$.

The ambient temperature when this experiment was implemented was about $19.7^{\circ} \mathrm{C}$ with a $6 \mathrm{~kW}$ microwave irradiation of $10 \mathrm{~s}$. The temperature distribution features of tested scraps were:

- The temperature distribution of the PVC scraps was $23.3-26.5^{\circ} \mathrm{C}$, the $25 \%$ percentile was about $24{ }^{\circ} \mathrm{C}$, the $75 \%$ percentile was about $25^{\circ} \mathrm{C}$, and the median temperature was about $24.4^{\circ} \mathrm{C}$.

- The temperature distribution of the ABS scraps was $25-28.3{ }^{\circ} \mathrm{C}$, the $25 \%$ percentile was about $25.7^{\circ} \mathrm{C}$, the $75 \%$ percentile was about $27.3^{\circ} \mathrm{C}$, and the median temperature was about $26.9^{\circ} \mathrm{C}$.

- The temperature distribution of the PP scraps was $27.3-30.5^{\circ} \mathrm{C}$, the $25 \%$ percentile was about $27.8^{\circ} \mathrm{C}$, the $75 \%$ percentile was about $28.9^{\circ} \mathrm{C}$, and the median temperature was about $27.9^{\circ} \mathrm{C}$.

- The temperature distribution of the EPDM scraps was $34.8-44.9^{\circ} \mathrm{C}$, the $25 \%$ percentile was about $35.4{ }^{\circ} \mathrm{C}$, the $75 \%$ percentile was about $41^{\circ} \mathrm{C}$, and the median temperature was about $39.2{ }^{\circ} \mathrm{C}$.

- The temperature distribution of the NBR scraps was $37-49.6{ }^{\circ} \mathrm{C}$, the $25 \%$ percentile was about $38.2{ }^{\circ} \mathrm{C}$, the $75 \%$ percentile was about $45.2^{\circ} \mathrm{C}$, and the median temperature was about $42.7^{\circ} \mathrm{C}$.

- The temperature distribution of the $\mathrm{CR}$ scraps was $47.2-58{ }^{\circ} \mathrm{C}$, the $25 \%$ percentile was about $49.1{ }^{\circ} \mathrm{C}$, the $75 \%$ percentile was about $54.2^{\circ} \mathrm{C}$, and the median temperature was about $52.5^{\circ} \mathrm{C}$.

- The temperature distribution of the SBR scraps was $52.4-64{ }^{\circ} \mathrm{C}$, the $25 \%$ percentile was about $53.3{ }^{\circ} \mathrm{C}$, the $75 \%$ percentile was about $59.3^{\circ} \mathrm{C}$, and the median temperature was about $57.8^{\circ} \mathrm{C}$.

- The temperature rising effects of the tested ELV polymer scraps of PVC, ABS, PP, EPDM, NBR, $\mathrm{CR}$, and SBR under the irradiation power of $9 \mathrm{~kW}$, respectively, are shown in Figure 14.

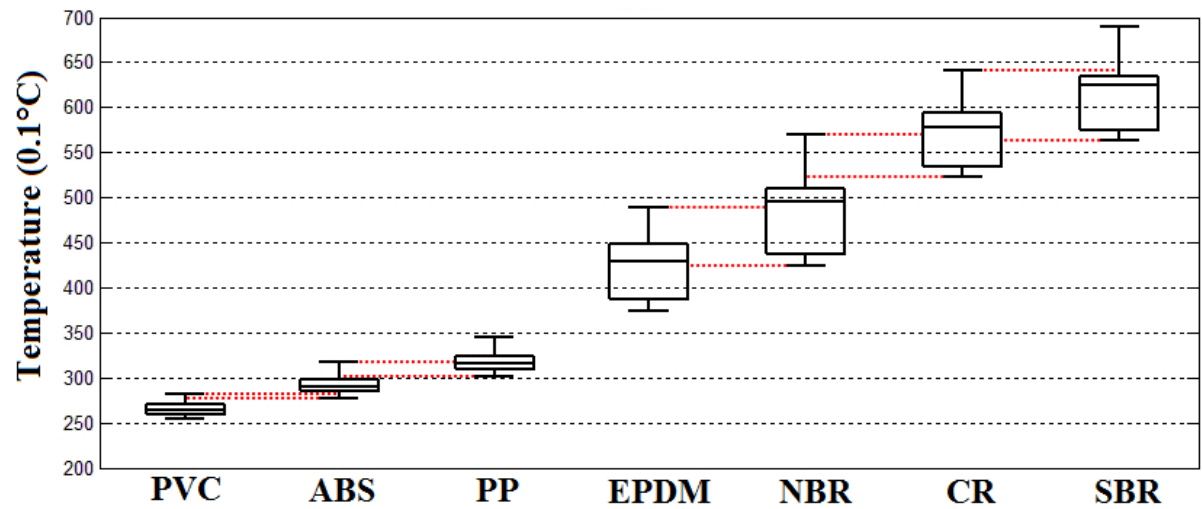

Figure 14. Distribution of temperature rises on tested polymer samples under microwave irradiation power of $9 \mathrm{~kW}$. 
The ambient temperature when this experiment was implemented was about $20.8^{\circ} \mathrm{C}$ with a $9 \mathrm{~kW}$ microwave irradiation of $10 \mathrm{~s}$. The temperature distribution features of tested scraps were:

- The temperature distribution of the PVC scraps was $25.5-28{ }^{\circ} \mathrm{C}$, the $25 \%$ percentile was about $26{ }^{\circ} \mathrm{C}$, the $75 \%$ percentile was about $27.5^{\circ} \mathrm{C}$, and the median temperature was about $27^{\circ} \mathrm{C}$.

- The temperature distribution of the ABS scraps was $27.8-32.3^{\circ} \mathrm{C}$, the $25 \%$ percentile was about $28.5^{\circ} \mathrm{C}$, the $75 \%$ percentile was about $30^{\circ} \mathrm{C}$, and the median temperature was about $29^{\circ} \mathrm{C}$.

- The temperature distribution of the PP scraps was $30.1-34.8{ }^{\circ} \mathrm{C}$, the $25 \%$ percentile was about $31.1{ }^{\circ} \mathrm{C}$, the $75 \%$ percentile was about $32.5^{\circ} \mathrm{C}$, and the median temperature was about $31.9^{\circ} \mathrm{C}$.

- The temperature distribution of the EPDM scraps was $37.5-49{ }^{\circ} \mathrm{C}$, the $25 \%$ percentile was about $33.8^{\circ} \mathrm{C}$, the $75 \%$ percentile was about $45^{\circ} \mathrm{C}$, and the median temperature was about $43.1^{\circ} \mathrm{C}$.

- The temperature distribution of the NBR scraps was $42.5-57.2^{\circ} \mathrm{C}$, the $25 \%$ percentile was about $43.8{ }^{\circ} \mathrm{C}$, the $75 \%$ percentile was about $51{ }^{\circ} \mathrm{C}$, and the median temperature was about $49.8^{\circ} \mathrm{C}$.

- The temperature distribution of the CR scraps was $52.4-64{ }^{\circ} \mathrm{C}$, the $25 \%$ percentile was about $53.5{ }^{\circ} \mathrm{C}$, the $75 \%$ percentile was about $59.5^{\circ} \mathrm{C}$, and the median temperature was about $57.8^{\circ} \mathrm{C}$.

- The temperature distribution of the SBR scraps was $57-69^{\circ} \mathrm{C}$, the $25 \%$ percentile was about $57.7^{\circ} \mathrm{C}$, the $75 \%$ percentile was about $63.3^{\circ} \mathrm{C}$, and the median temperature was about $62.6^{\circ} \mathrm{C}$.

\subsection{Analysis and Discussion}

According to the results of the experiments, it was found that the microwave heating behaviors of plastics and elastomers were significantly different. Elastomers were much more sensitive to microwave radiation than plastics, which meant that the dielectric additive agents were much more active in the elastomer molecules than in the plastics. In all three power tests at 3, 6 and $9 \mathrm{~kW}$, the mixture of the plastic group (PVC, PP, and ABS) and the mixture of elastomer group (EPDM, NBR, CR, and SBR) were successfully separated with an efficiency of $100 \%$. Due to the insensitivity of plastics in microwave irradiation, their temperature variation ranges were very small. However, for the elastomers, their variation ranges were much broader than that of the plastics.

In both groups of plastics and elastomers, the temperature distribution ranges of all sorts of materials overlapped, which meant that $100 \%$ separation efficiency could not be achieved. Of course, there is no currently available technology that can totally separate these mixtures. The overlapping ranges of temperature distributions are illustrated in Figures 11-13 with red dotted lines. Within the overlapping area means that at least two kinds of tested scraps that could be confused. According to the figure diagrams, there was no overlapping of three kinds of materials, which means at least the mixtures of seven kinds of polymers could be at least sorted to be mixtures of two kinds of materials with an efficiency of $100 \%$, which could make it convenient to a large extent for the further processing and recycling of ASRs.

Of course, sorting the ASR polymer mixture only into plastic- and elastomer groups was not the aim of this research. Through further analysis of the overlap range of temperature distribution, between the overlapped ranges, there were still specific ranges where the single materials could be fully sorted to produce pure products. These ranges were named as feature temperatures for the corresponding type of polymer. The feature temperature ranges and the mass of corresponding scraps within the feature ranges are demonstrated in Table 2 as follows:

From Table 2 it can be seen that under the microwave irradiation power of $3 \mathrm{~kW}$, there was a total of $170.51 \mathrm{~kg}$ of polymer materials that could be recognized and fully sorted, which represented about $75.04 \%$ of the mass of all the tested samples, where the sorting efficiency of PP could achieve $92.3 \%$, SBR could achieve $84.9 \%$, CR was $79.4 \%$, and for ABS it was $73.3 \%$. However, for EPDM, the sorting efficiency was $46.52 \%$, which was lower than $50 \%$, moreover, for NBR it was $31 \%$ and for PVC on which the heating effect was very limited, it was only $10.4 \%$. 
Table 2. Feature temperature ranges corresponding to the tested polymer masses/proportions.

\begin{tabular}{ccccccc}
\hline \multirow{2}{*}{ Materials } & \multicolumn{2}{c}{$\mathbf{3 ~ k W}$} & \multicolumn{2}{c}{$\mathbf{6 ~ k W}$} & \multicolumn{2}{c}{$\mathbf{9 ~ k W}$} \\
\cline { 2 - 7 } & $\begin{array}{c}\text { Feature } \\
\text { Range/ }\end{array}{ }^{\circ} \mathbf{C}$ & $\begin{array}{c}\text { Mass/kg } \\
\text { (Proportion/\%) }\end{array}$ & $\begin{array}{c}\text { Feature } \\
\text { Range/ } /{ }^{\circ} \mathbf{C}\end{array}$ & $\begin{array}{c}\text { Mass/kg } \\
\text { (Proportion/\%) }\end{array}$ & $\begin{array}{c}\text { Feature } \\
\text { Range } /{ }^{\circ} \mathbf{C}\end{array}$ & $\begin{array}{c}\text { Mass/kg } \\
\text { (Proportion/\%) }\end{array}$ \\
\hline SBR & $51-57.6$ & $76.64(84.9 \%)$ & $58-64$ & $55.33(61.3 \%)$ & $64-69$ & $20.40(22.6 \%)$ \\
CR & $41.1-47.6$ & $7.54(79.4 \%)$ & $49.6-52.4$ & $3.54(37.3 \%)$ & $57.2-57$ & $(0 \%)$ \\
NBR & $37.2-40.2$ & $4.0(31.0 \%)$ & $44.9-47.2$ & $2.23(17.6 \%)$ & $49-52.4$ & $3.57(27.6 \%)$ \\
EPDM & $27.8-32.2$ & $14.21(46.5 \%)$ & $37.5-42.5$ & $6.75(22 \%)$ & $37.5-42.5$ & $13.96(45.4 \%)$ \\
PP & $24-27.2$ & $49.65(92.3 \%)$ & $28.3-30.5$ & $30.2(56.2 \%)$ & $32.3-34.8$ & $27.60(51.3 \%)$ \\
PVC & $21-22$ & $1.12(10.4 \%)$ & $23.3-25$ & $4.65(73.3 \%)$ & $25.5-27.8$ & $5.48(86.4 \%)$ \\
ABS & $22-23.3$ & $17.35(73.3 \%)$ & $26.5-27.3$ & $8.26(35 \%)$ & $28-30.1$ & $12.32(52.1 \%)$ \\
\hline
\end{tabular}

Under the microwave irradiation power of $6 \mathrm{~kW}$, there was a total of $110.93 \mathrm{~kg}$ of polymer materials that could be recognized and fully sorted which represented about $48.82 \%$ mass of all the tested samples where the sorting efficiency of PP was reduced to $56.2 \%$, for SBR it was reduced to $61.3 \%$, for CR it was reduced to $37.3 \%$, and for ABS it was reduced to $35 \%$. For EPDM, the sorting efficiency was also reduced to $22 \%$, and for NBR it was reduced to $17.6 \%$. However, for PVC, it increased to $73.3 \%$. With the exception of PVC, the sorting efficiency of the other six kinds of tested polymers were reduced to a large extent.

Furthermore, under the microwave irradiation power of $9 \mathrm{~kW}$, a total of $83.33 \mathrm{~kg}$ of polymer materials could be recognized and fully sorted, which represented about $36.67 \%$ mass of all the tested samples. The sorting efficiency of PP was further reduced to $51.3 \%$. For SBR, it was further significantly reduced to $22.6 \%$, for $C R$ it was reduced to $0 \%$ since the feature temperature range of NBR and SBR fully occupied the feature temperature range of CR. For ABS, it increased again to $52.1 \%$, but was still lower than the $3 \mathrm{~kW}$ test. Additionally, for EPDM, the sorting efficiency increased again to $45.4 \%$, but it was also lower than the $3 \mathrm{~kW}$ test. For NBR, it increased again to $27.6 \%$, but was also lower than the $3 \mathrm{~kW}$ test, which was the same phenomenon as the ABS. Only for PVC did the sorting efficiency keep increasing to $86.4 \%$.

The results of this study demonstrated that by using microwave heating effects on polymers, more than $75 \%$ of the mass of the seven kinds of ASR tested materials could be recognized and sorted. However, the sorting efficiency could not be increased by increasing the irradiation power of the microwave, on the contrary, this research indicated that by increasing the microwave power from 3 to $6 \mathrm{~kW}$ and then $9 \mathrm{~kW}$, the sorting efficiency decreased from $75.04 \%$ to become $48.82 \%$ and further decreased to $36.67 \%$. The highest sorting efficiency was obtained with the lowest irradiation power. The reason for this phenomenon was due to the heating behavior of the polymer materials. Through the statistics of the feature temperature distributions of tested polymers, it was found that with the increase of microwave power, the feature temperature distributions became wider. Hence, the overlapping of feature temperature ranges between adjacent materials became more serious, which limited the successful recognition during the polymer sorting process. An extreme situation was under the irradiation power of $9 \mathrm{~kW}$ where the recognition of CR became impossible as its feature temperature range was fully overlapped by NBR and SBR.

Although for some kinds of polymers like ABS, EPDM, and NBR, the sorting efficiency increased from 6 to $9 \mathrm{~kW}$, they were still lower than the results of $3 \mathrm{~kW}$. The only exception was PVC, whose sorting efficiency kept increasing with the increase of microwave power. The reason is that PVC is much more insensitive to microwave radiation than other materials, which made its temperature distribution range much less than the adjacent materials like ABS and PP, which always led its temperature distribution being separated from the others with the rise in irradiation power.

The results also indicated that the microwave sensitivities of the elastomers were much higher that the plastics, which meant that the group of tested plastic mixture and the group of tested elastomer mixture could be $100 \%$ separated. This indicates that in plastic materials, the dielectric additive 
agents were much more stable than those in the elastomers under microwave irradiation. Furthermore, increasing the temperature in polymers, especially in elastomers, could probably have further enhanced the activities of dielectric additives like soot, which led to a wider distribution of feature temperature and further limited the sorting efficiency. According to the theoretical model of Equations (1)-(3), and with the help of the laser-triangulation measurement, more detailed research on microwave energy attenuation and transfer behavior by transmission through each kind of tested polymers with specific thickness could be implemented.

None of the seven tested types of polymers could be fully sorted from the mixture, moreover, the results also showed that to achieve $100 \%$ sorting efficiency, the minimum variations of the feature temperature distribution between the two kinds of materials were about $5^{\circ} \mathrm{C}$ and $10.5{ }^{\circ} \mathrm{C}$ for plastics and elastomers, respectively, under the irradiation power of $3 \mathrm{~kW}$, as well as an irradiation period of $10 \mathrm{~s}$.

\section{Conclusions}

This research verified that by using the heating effects of S-band microwave irradiation, the polymer materials in ELVs could be recognized and sorted. For a mixture consisting of seven kinds of polymers (PVC, ABS, PP, EPDM, NBR, CR, and SBR) we could achieve a maximum sorting efficiency of $75 \%$ (mass) under an irradiation power of $3 \mathrm{~kW}$ with irradiation period of $10 \mathrm{~s}$. Furthermore, under this condition, the SBR, PP, and ABS achieved a high efficiency of recognition with $84.9 \%, 92.3 \%$, and $73.3 \%$ in mass, respectively.

With this method, the plastic group (PVC, PP, and ABS) and elastomer group (EPDM, NBR, CR, and SBR) could be $100 \%$ distinguished, since the plastics were much more insensitive to microwave irradiation than the elastomers. The reason could be that the dielectric additives in elastomers have more freedom than in plastics, which led to more thermal generation through vibrations caused by the microwave. The experimental phenomenon proved that with the increase of irradiation power, the increase of feature temperature distribution ranges on elastomers became much larger than those of the plastics, which meant that in the elastomers, higher temperatures gave more freedom to the dielectric molecules.

A wider distribution of feature temperatures led to overlapping between the different polymers and further caused a significant decrease of the sorting efficiency. Therefore, in this research, we found that with the increase of irradiation power, the sorting efficiency decreased. The sorting efficiencies were $75.04 \%, 48.82 \%$, and $36.67 \%$ in mass under the irradiation power of $3 \mathrm{~kW}, 6 \mathrm{~kW}$, and $9 \mathrm{~kW}$, respectively.

Although none of the seven kinds of tested polymers could be fully sorted from the mixture, this research has made progress and represents a major innovation in the material recycling of ELV polymers, despite the fact there still no effective method to completely sort them. The results also showed that to achieve $100 \%$ sorting efficiency, the minimum variations of feature temperature distribution between two kinds of materials are about $5^{\circ} \mathrm{C}$ and $10.5^{\circ} \mathrm{C}$ for plastics and elastomers, respectively, under the irradiation power of $3 \mathrm{~kW}$ and the irradiation period of $10 \mathrm{~s}$.

Some specific polymers could also be sensitive to microwaves of other frequency domains and bands. In our future research work, the heating effects of other microwave irradiation frequencies will be studied, and the microwave acting effects on additive agents could also be studied, since the sensitivity difference of additive agents determines the heating features of the polymers and may have provide more detailed variations under different microwave frequencies.

Author Contributions: J.H. and Z.Z. conceived and designed the experiments; Z.B. made the Validation. C.T., Z.Z. and J.H. performed the experimental work; C.T. and Z.Z analyzed the data; all authors contributed to the writing, reviewing of the manuscript, as well as the interpretation of the experimental results.

Funding: This research was funded by National Natural Science Foundation of China (NSFC), grant No. U1710120; and China Fundamental Research Funds for the Central Universities, grant No. 2015QNA28. 
Acknowledgments: This work was funded by the projects "National Natural Science Foundation of China U1710120" and the "China Fundamental Research Funds for the Central Universities 2015QNA28". My doctoral supervisor Thomas Pretz from RWTH Aachen University, as well as former colleagues Yvonne Schockert and Yunxia $\mathrm{Wu}$ are acknowledged for leading me into this research area.

Conflicts of Interest: The authors declare no conflict of interest.

\section{References}

1. Vermeulen, I.; Van Caneghem, J.; Blocka, C.; Baeyensc, J.; Vandecasteele, C. Automotive shredder residue (ASR): Reviewing of its production from end-of-life vehicles (ELV's) and its recycling energy or chemical's valorization. J. Hazard. Mater. 2011, 190, 8-27. [CrossRef] [PubMed]

2. Van Caneghem, J.; Block, C.; Van Brecht, A.; Wauters, G.; Vandecasteele, C. Mass balance for POPs in hazardous and municipal solid waste incinerators. J. Chemosphere 2010, 78, 701-708. [CrossRef] [PubMed]

3. Huang, J.; Tian, C.Y.; Ren, J.W.; Bian, Z.F. Study on Impact Acoustic-Visual Sensor-Based Sorting of ELV Plastic Materials. Sensors 2017, 17, 1325. [CrossRef] [PubMed]

4. Pan, Y.X.; Li, H.T. Sustainability evaluation of end-of-life vehicle recycling based on emergy analysis: A case study of an end-of-life vehicle recycling enterprise in China. J. Clean. Prod. 2016, 131, 219-227. [CrossRef]

5. Huang, J. Feasibility Research on Sorting of Black and Dark Dyed Waste Plastics Using Impact Acoustic Emission; Shaker Verlag: Herzogenrath, Germany, 2014.

6. Simic, V. Fuzzy risk explicit interval linear programming model for end-of-life vehicle recycling planning in the EU. Waste Manag. 2015, 35, 265-282. [CrossRef] [PubMed]

7. Santinia, A.; Herrmannb, C.; Passarinia, F.; Vassuraa, I.; Lugerb, T.; Morsellia, L. Assessment of Ecodesign potential in reaching new recycling targets. Resour. Conserv. Recycl. 2010, 54, 1128-1134. [CrossRef]

8. Ohno, H.; Matsubae, K.; Nakajima; Kondo, Y.; Nakamura, S. Toward the efficient recycling of alloying elements from end of life vehicle. Resour. Conserv. Recycl. 2015, 100, 11-20. [CrossRef]

9. Huang, J.; Bian, Z.F.; Lei, S.G. Feasibility Study of Sensor Aided Impact Acoustic Sorting of Plastic Materials from End-of-Life Vehicles (ELVs). Appl. Sci. 2015, 5, 1699-1714. [CrossRef]

10. Huang, J. Resource Recycling and Utilization Technologies of Industrial and Mining Solid Wastes; Publishing House CUMT: Xuzhou, China, 2017.

11. Bonifazi, G.; Serranti, S. Recycling Technologies. In Encyclopedia of Sustainability Science and Technology; Springer: New York, NY, USA, 2012; pp. 8794-8848.

12. Vajna, B.; Palásti, K.; Bodzay, B.; Toldy, A.; Patachia, S.; Buican, R.; Catalin, C.; Tierean, M. Complex analysis of car shredder light fraction. J. Red 2010, 2, 2-50. [CrossRef]

13. Vegas, I.; Broos, K.; Nielsen, P.; Lambertz, O.; Lisbona, A. Upgrading the quality of mixed recycled aggregates from construction and demolition waste by using near-infrared sorting technology. J. Constr. Build. Mater. 2015, 75, 121-128. [CrossRef]

14. Bezati, F.; Froelich, D.; Massardier, V.; Maris, E. Addition of tracers into the polypropylene in view of automatic sorting of plastic wastes using X-ray fluorescence spectrometry. Waste Manag. 2010, 30, 591-596. [CrossRef] [PubMed]

15. Wu, G.; Li, J.; Xu, Z. Triboelectrostatic separation for granular plastic waste recycling: A review. Waste Manag. 2013, 33, 585-597. [CrossRef] [PubMed]

16. Xue, M.Q.; Li, J.; Xu, Z.M. Environmental Friendly Crush-Magnetic Separation Technology for Recycling Metal-Plated Plastics from End-of-Life Vehicles. Environ. Sci. Technol. 2012, 46, 2661-2667. [CrossRef] [PubMed]

17. Wang, C.Q.; Wang, H.; Liu, Q.; Fu, J.G.; Liu, Y.N. Separation of polycarbonate and acrylonitrile-butadiene-styrene waste plastics by froth flotation combined with ammonia pretreatment. Waste Manag. 2014, 34, 2656-2661. [CrossRef] [PubMed]

18. Wang, C.Q.; Wang, H.; Fu, J.G.; Liu, Y.N. Flotation separation of waste plastics for recycling-A review. Waste Manag. 2015, 41, 28-38. [CrossRef] [PubMed]

19. Li, J.; Wu, G.Q.; Xu, Z.M. Tribo-charging properties of waste plastic granules in process of tribo-electrostatic separation. Waste Manag. 2015, 35, 36-41. [CrossRef] [PubMed]

20. Gundupalli, S.P.; Hait, S.; Thakur, A. A review on automated sorting of source-separated municipal solid waste for recycling. Waste Manag. 2017, 60, 56-74. [CrossRef] [PubMed] 
21. Pomykala, J.A., Jr.; Jody, B.J.; Daniels, E.J.; Spangenberger, J.S. Automotive recycling in United States: Energy conversion and environment benefits. JOM 2007, 59, 41-45. [CrossRef]

22. Jähne, B. Digital Image Processing; Springer: Berlin/Heidelberg, Germany, 2005.

23. Singh, V.K.; Shukla, A.; Patra, M.K.; Sainib, L.; Janib, R.K.; Vaderab, S.R.; Kumar, N. Microwave absorbing properties of a thermally reduced graphene oxide/nitrile butadiene rubber composite. J. Carbon 2012, 50, 2202-2208. [CrossRef]

24. Flaifel, M.H.; Ahmad, S.H.; Hassan, A.; Bahric, S.; Tarawneha, M.A.; Yu, L.J. Thermal conductivity and dynamic mechanical analysis of NiZn ferrite nanoparticles filled thermoplastic natural rubber nanocomposite. J. Compos. Part B Eng. 2013, 52, 334-339. [CrossRef]

25. Chen, H.L.; Li, T.; Liang, Y.; Sun, B.; Li, Q.L. Experimental study of temperature distribution in rubber material during microwave heating and vulcanization process. J. Heat Mass Transf. 2017, 53, 1051-1060. [CrossRef]

26. Chen, H.L.; Li, T.; Li, K.L.; Li, Q.L. Experimental and numerical modeling research of rubber material during microwave heating process. J. Heat Mass Transf. 2017, 1-12. [CrossRef]

27. Ragosta, G.; Musto, P.; Martuscelli, E. Recycling of plastic car components: The case of a multilayer item based on polypropylene. J. Mater. Sci. 2000, 35, 3741-3751. [CrossRef]

28. Kong, I.; Ahmad, S.H.; Abdullah, M.H.; Hui, D.; Yusoff, A.N.; Puryanti, D. Magnetic and microwave absorbing properties of magnetite-thermoplastic natural rubber nanocomposites. J. Magn. Magn. Mater. 2010, 322, 3401-3409. [CrossRef]

29. Movahed, S.O.; Ansarifar, A.; Karbalaee, S.; Far, S.A. Devulcanization and recycling of waste automotive EPDM rubber powder by using shearing action and chemical additive. J. Prog. Rubber Plast. Recycl. Technol. 2015, 31, 87-117.

30. Stephensen, E.; Adolfsson-Erici, M.; Celander, M.; Hulander, M.; Parkkonen, J.; Hegelund, T.; Sturve, J.; Hasselberg, L.; Bengtsson, M. Biomarker responses and chemical analyses in fish indicate leakage of polycyclic aromatic hydrocarbons and other compounds from car tire rubber. Environ. Toxicol. Chem. 2003, 22, 2926-2931. [CrossRef] [PubMed]

31. Ma, S.C.; Yao, J.J.; Jin, X.; Cui, J.W.; Ma, J.X. Progress for Thermal and Non-thermal Effects of Microwave Chemistry. J. Chem. Bull. 2011, 74, 41-46. (In Chinese)

32. Li, T.; Chen, H.L.; Yang, G.Z.; Du, D.X.; Li, Q.L. The Study on the Numerical Simulation of Rubber Microwave Heating. J. Eng. Thermophys. 2012, 33, 1559-1562. (In Chinese)

33. Alin, J.; Hakkarainen, M. Type of polypropylene material significantly influences the migration of antioxidants from polymer packaging to food simulants during microwave heating. J. Appl. Polym. Sci. 2010, 118, 1084-1093. [CrossRef]

34. Glowaz, A.; Glowacz, Z. Diagnosis of the three-phase induction motor using thermal imaging. Infrared Phys. Technol. 2017, 81, 7-16. [CrossRef]

35. Singh, G.; Naikan, V.N.A. Infrared thermography based diagnosis of inter-turn fault and cooling system failure in three phase induction motor. Infrared Phys. Technol. 2017, 87, 134-138. [CrossRef] 